\title{
The Chief Information Officer: A Review of the Role
}

\author{
Gordon Hunter \\ University of Lethbridge, Lethbridge, Alberta, Canada
}

ghunter@uleth.ca

\begin{abstract}
The role of Chief Information Officer (CIO) is a relatively new one and it is evolving. Issues surround the role related to performance, evaluation, and turnover. The investigation reported here is the result of in-depth qualitative interviews with currently practicing CIOs from New Zealand, Taiwan, and the United States. The results are presented in relation to issues that the CIO initially had to deal with, current issues, and future issues as anticipated by the CIOs. Two major contributions of this research relate to culture and alignment. From a cultural perspective there is little variability in the roles. However, how the roles are carried out will be affected more by corporate culture than by societal culture. Alignment is related to the expectations of senior management and the interpretation by the CIO. It is very important to the CIO and senior management that there is understanding and agreement regarding role expectations. This project contributes to a more thorough understanding of the role of the $\mathrm{CIO}$ and how it is evolving in various contexts.
\end{abstract}

Keywords: Chief Information Officer; Narrative Inquiry; Long Interview Technique; Interview Protocol

\section{Introduction}

The establishment of the Chief Information Officer (CIO) role suggests that senior management formally recognize that information is a valuable resource and must be managed at a senior level within the organization. However, currently, there is a very high turnover in those individuals who fill the CIO position. Capella (2006) suggests the turnover rate of CIOs is twice that of Chief Financial Officers (CFO) and Chief Executive Officers (CEO). It might be related to an unclear definition of duties. Perhaps performance evaluation factors may not be specific or agreed upon by senior management (Marchand, 2008). Demand for CIOs in many organizations may result in voluntary turnover. Further, the $\mathrm{CIO}$ has only 100 days to prove his or her value to the organization and senior management (Capella, 2006).

The emergence of a new breed of manager, the Chief Information Officer (CIO) was reported by Bock, Carpenter, and Davis (1986) in Business Week. This new position was supposed to provide a link between the data processing department and the company's senior managers. Thus, the data

Material published as part of this publication, either on-line or in print, is copyrighted by the Informing Science Institute. Permission to make digital or paper copy of part or all of these works for personal or classroom use is granted without fee provided that the copies are not made or distributed for profit or commercial advantage AND that copies 1) bear this notice in full and 2) give the full citation on the first page. It is permissible to abstract these works so long as credit is given. To copy in all other cases or to republish or to post on a server or to redistribute to lists requires specific permission and payment of a fee. Contact Publisher@InformingScience.org to request redistribution permission. processing manager position was becoming recognized as a $\mathrm{CIO}$ in a similar manner as twenty years before when accountants were elevated to the CFO position. The emergence of the $\mathrm{CIO}$ role suggests that companies were recognizing the strategic importance of information and its supporting technology. 
If the application of information technology is going to be successful, a team approach is necessary at the senior level in the organization (Maciag, 2002). So, the CIO must attempt to bridge the gap between information technology and the business. However, other members of the senior management committee must become aware of information technology and related processes and how these may be applied to other functional areas within the organization. The major underlying factor for this situation is related to the alignment of expectations of the $\mathrm{CIO}$ and other members of the senior management committee.

The objective of this research project was to investigate these issues and others related to the emerging and evolving role of the CIO. The goal was to document these issues as identified by the $\mathrm{CIO}$ and to explore the issues relative to various corporate and national contexts. A crosscultural investigation was also conducted in an attempt to determine if this newly emerging role is being impacted by societal culture. Thus, in-depth exploratory one-on-one interviews were conducted to document CIOs' comments about those issues which they considered significant.

This document is structured in the following manner. The next section presents a review of current research and is organized into two categories of investigations related to the organization and the individual role. This latter category is the focus of the research project reported here in the subsequent section. Next, the findings of this research are reported organized by CIO comments about initial, current, and future issues. This sequence of issues was chosen in an attempt to identify any trends in the $\mathrm{CIO}$ role. The discussion section provides comments about alignment and culture as they relate to the CIO role. Finally, conclusions are presented about the emerging CIO role.

\section{Current Research}

The discussion of research related to the role of the CIO is presented here in two categories. The first category relates to organizational aspects of the CIO role and the relationship of the CIO to both the overall company and the functional unit of the CIO. This category provides the context for the second category, which is the focus of this research project. The second category discusses research related to investigating various aspects of the emerging role of the CIO.

\section{Organizational Aspects Research}

The perception of the CIO role within the company is evolving (Patten, Fjermestad, \& Whitworth, 2009). Senior management's attitude is that managing information strategically should be fully integrated with the business (Peppard, 2007) and also should be regarded in a similar vein as managing finances, human resources, operations, and the other major functions of the company (Meagher, 2003). This attitude is reflected in the movement of the CIO position to the board level (Kolbasuk, 2005; Ranganathan \& Jha, 2008) where information technology is regarded strategically (Reich \& Nelson, 2003) to facilitate competitive advantage. The existence of a steering committee (Karimi, Bhattacherjee, Gupta, \& Somers, 2000) also provides evidence of the strategic use of information technology and its link with the overall business goals.

Alignment is another theme of research at the corporate level (Bassellier, Gagnon, \& Pinsonneault, 2008; Weiss, Thorogood, \& Clark, 2006; Yayla \& Hu, 2009). Information technology and business alignment refers to coordinating the capabilities of information technology with the goals of the business and by demonstrating clear business related value from IT (Scott, 2007). The business plan should attempt to take full advantage of available technologies (Hartung, Reich, \& Benbasat, 2000). Also, alignment is facilitated through communication (Johnson \& Lederer, 2007; Reich \& Benbasat, 2000). It is important that all senior managers acquire shared domain knowledge (Andriole, 2009). Thus, technical professionals must learn about the business, and business professionals must learn about technology. As Reich and Benbasat (2000) suggest 
managers with both business and information technology knowledge will be catalysts for the innovative application of technology to support business goals. Dickerson (2004) has suggested that alignment is also facilitated through the efforts of the CIO to manage partners and to provide information technology leadership.

Some research has been conducted at the functional unit level which reports directly to the CIO. Feeny and Willcocks (1998a, 1998b) suggest that the capabilities of the information systems business unit should facilitate a company's ability to exploit information technology. A skill set to support this capability would consist of technical skills, business knowledge, and interpersonal skills. This is similar to the original findings of Todd, Mckeen, and Gallupe (1995). More recently Van der Heijden (2001) has suggested that a capability perspective will help focus efforts on addressing issues rather than simply treating symptoms. Further, Feeny and Willcocks (1998a, 1998b), subsequently supported by Cash (2005), suggest that these capabilities must be able to support the attainment of the company's goals and objectives.

A number of investigations (Bharadwaj, 2000; Bharadwaj, Sambamurthy, \& Zmud, 1999; Cash, 2005; Feeny \& Willcocks, 1998a, 1998b; McKeen, Smith, \& Jin, 2009; Van der Heijden, 2001) have focused on identifying core capabilities within the CIO function for exploiting information technology.

Feld and Stoddard (2004) suggest that successfully implementing information technology must consider factors beyond the technology itself. They state the following:

"Making IT work has little to do with technology itself. Just because a builder can acquire a handsome set of hammers, nails, and planks doesn't mean he can erect a quality house at reasonable cost. Making IT work demands the same things that other parts of the business do - inspired leadership, superb execution, motivated people, and the thoughtful attention and high expectations of senior management." (p. 74)

\section{Emerging CIO Role Research}

In 1998 Korn/Ferry International published the results of an international survey of three hundred and forty CIOs employed by "Times 1000" companies about their changing role within their organization. When the survey results were published in 1998 it was concluded that CIOs found themselves drifting between a technically oriented past and a strategic business oriented future. The past related to a focus on efficiently employing state of the art hardware and software. While the future indicated increasing involvement in strategic business planning at the most senior organizational level. The report further indicated that those organizations that can successfully manage the transition of this role will gain competitive advantage. Thus, it is important that both the company and the CIO realize that the CIO role should evolve from an information processing function to a role based upon knowledge management and innovation (Newbold \& Azua, 2007).

Jones and Arnett (1994) suggested that the CIO role emerged so that one senior executive could be assigned the overall corporate responsibility for an organization's information processing needs. The gap between the organizational and information strategies (Stephens, Ledbetter, Mitra, \& Foord, 1992) had to be addressed and resolved (Stephens \& Loughman, 1994). It was considered important both for survival and to attain competitive advantage that the business goals are reflected in the actions of the information technology function (Earl \& Feeny, 1994).

Todd et al. (1995) reviewed job advertisements for information systems positions over a twenty year period from 1970 to 1990 . For the information system manager position they determined a common thread relating to a blend of technical skill and business knowledge, coupled with effective interpersonal skills. Over the years while these components have remained consistent, it is the mix that has changed. Andrews and Carlson (1997) have suggested that the role of the CIO 
has past through many phases and is in the fourth wave. To begin, the first wave portrayed CIOs as simply glorified data processing managers. The second wave saw CIOs perform their role as technocrats representing the expertise of the technology and its application. In the third wave CIOs adopted the business executive perspective. Currently, in the fourth wave the CIO is working at combining the technocrat and the business perspectives. Arnold (2001) supported this evolution suggesting that, while CIOs must still be knowledgeable about technology, they should also be sure to build relationships with other senior members of the organization and to think strategically regarding the application of technology for the overall benefit of the company.

The role of the CIO is expanding to include more risk assessment, change management, problem solving, and selling at the organizational level (Dittmar \& Kobel, 2008; Weiss \& Anderson, 2004).

Comments about what the future holds for CIOs are also interesting. For instance, the Nolan Norton Institute (2001) suggested that the senior information technology executive is moving away from the "technology" and emphasizing more of the "information". The CIO is becoming more of a "prophet" and less of a "technologist". As a prophet the CIO must know how technology may be employed to transform the business. Further, the CIO must be capable of leading the more traditional parts of the organization through this transition. Olson (2000) used the term "apostle" in reference to the future role of the CIO. While CIOs must educate the rest of the organization about the capabilities of information technology, they cannot become too enthusiastic and attempt to push the organization beyond the willingness of the CEO and the rest of the senior management team. A good CIO must develop a thorough understanding of the goals of the organization and how information technology may be strategically applied to advance towards those goals. More recently, Blair (2005) cautions, however, that while there is a movement toward more of an emphasis for the CIO to understand the business, the CIO must still be the information technology champion within the organization. The CIO needs to know both the business and the information technology. Thus, while the CIOs of the future will be involved in strategy, they must continue to understand information technology and how it can be applied to positively impact the business.

Unfortunately, it has been determined that the CIO still is held in lower regard than other members of the senior management team (Kaarst-Brown, 2005). Reasons for this situation include:

- Personality conflicts

- Lack of corporate technology vision

- Poorly aligned IT goals

- Lack of business knowledge

- Lack of IT awareness among business executives

- Incorrect formal structure and reporting relationships

The project reported here has investigated the evolving CIO role. In-depth qualitative interviews were employed to elicit comments and develop a better understanding of this role. The results of this exploratory investigation will expand our understanding in this area through a discussion of the evolving role of the $\mathrm{CIO}$.

\section{Project}

A Grounded Theory (Glaser \& Strauss, 1976) perspective was taken for this investigation, which suggests that qualitative data are gathered related to a research question from research participants who have experience and knowledge of the area under investigation. Further, a qualitative 
research approach was adopted based upon Narrative Inquiry which facilitates documenting research participant's recollections and interpretations of personal experiences. Narrative Inquiry involves, "... the symbolic presentation of a sequence of events connected by subject matter and related by time" (Scholes, 1981, p. 205) and includes the concepts of contextually rich and temporally bounded. Contextually rich recollections are those that are experienced first hand and are most vividly remembered (Swap, Schields, \& Abrams, 2001; Tulving, 1972). Stories that are temporally bounded have a beginning, a sequence of events, and an ending.

Before the interviews could be conducted it was necessary to find individuals who were interested in the project and who would be willing to volunteer to participate. Through various personal contacts individuals were sent information about the project. Those who responded expressing an interest in the project were contacted and provided further information. Individual interviews were scheduled with each CIO who volunteered. Some were conducted face-to-face, while others were carried out via the telephone. In all cases the interviews were audio taped. Transcripts were prepared from the audio tapes and sent to the respective participant for review. For the most part any corrections related to spellings of names or towns or were because of inaudible comments made during the interview.

In order to ground the discussion in the research participants' personal experiences an interview protocol (included here in the Appendix) was employed which guided a chronological discussion of the CIO's personal experience. The interview protocol was developed based upon the Long Interview Technique (McCracken, 1988). Questions were posed regarding the research participant's past career and personal experiences. A chronological process was followed from early life, through formal education, and into the various positions held throughout their career up until the current position. Then the detailed specific issues of the current position were investigated. Questions were asked about initial, current, and future issues.

The objective of this investigation was to document the comments of CIOs within their specific organization about the role they play. The Narrative Inquiry approach supports the objective of this project by facilitating an exploratory investigation of the issues involving the role of the CIO. During the course of the interview research participants were asked to reflect upon past work experiences. Initially, "grand tour" (McCracken, 1988) questions were asked. These questions are general in nature and non-directive in manner, allowing the research participant to specify much of the substance or perspective of the interview. Then the detailed specific issues of the current position were investigated. Questions were asked about initial, current, and future issues. Throughout this section of the interview, "floating prompt" (McCracken, 1988) questions were asked. The nature of these questions depends upon the content of each interview, and, generally, relate to the researcher's decision to pursue a thread of discussion in more detail. Another concept similar to floating prompts is "Laddering" (Stewart \& Stewart, 1981). This technique involves a series of "how" questions to facilitate the research participants' elaboration of their comments.

Specific or "planned prompt" (McCracken, 1988) questions were asked near the end of the interview in order to address issues gleaned from the literature or previous investigations. These planned prompts for this project related to:

- Personal history

- Previous experience

- Activities during a typical week

- Dealing with users

- Deciding on information technology investments 
Emerging themes were identified by analyzing individual interview transcripts and then by comparing the themes from other interview transcripts. This is a common and accepted practice when conducting qualitative research (Miles \& Huberman, 1994) to support the interpretation of textual data (Thompson, 1997). An iterative approach is taken to reviewing transcripts and identifying emerging themes. It may be necessary to review a transcript many times. The researcher must, "... be open to possibilities afforded by the text rather than projecting a predetermined system of meanings onto the textual data" (Thompson, 1997, p. 441).

\section{Findings}

The companies that employed the CIOs involved in the project are quite varied. Table 1 presents the some company demographics organized by country including the number of employees and the industry sector for each company.

Table 1. Company Demographics

\begin{tabular}{|c|c|c|}
\hline $\begin{array}{l}\text { Country: } \\
\text { Company }\end{array}$ & $\begin{array}{l}\text { Number of } \\
\text { Employees }\end{array}$ & $\begin{array}{l}\text { Industry } \\
\text { Sector }\end{array}$ \\
\hline \multicolumn{3}{|l|}{ New Zealand } \\
\hline 1 & 900 & Education \\
\hline 2 & 1,000 & Communications \\
\hline 3 & 4,653 & Construction \\
\hline 4 & 2,700 & Clothing \\
\hline 5 & 200 & Weather Reporting \\
\hline \multicolumn{3}{|l|}{ Taiwan } \\
\hline 1 & 5,000 & Airline \\
\hline 2 & 4,200 & Electronics \\
\hline 3 & 1,200 & Telecommunications \\
\hline 4 & 10,000 & Electronics \\
\hline 5 & 3,800 & Electronics \\
\hline 6 & 8,727 & Manufacturing \\
\hline \multicolumn{3}{|l|}{ United States } \\
\hline 1 & 8,000 & Manufacturing \\
\hline 2 & 1,300 & Library \\
\hline 3 & $\begin{array}{c}500-1,500 \\
\text { Seasonal }\end{array}$ & Manufacturing \\
\hline 4 & 2,200 & Communications \\
\hline 5 & 8,500 & Health Services \\
\hline 6 & 110,000 & Retail \\
\hline 7 & 3,500 & Manufacturing \\
\hline
\end{tabular}


Table 2 presents some demographic data about the CIOs who participated in the project.

Table 2. CIO Demographics

\begin{tabular}{|c|c|c|c|c|}
\hline & New Zealand & Taiwan & United States & Total \\
\hline \multicolumn{5}{|l|}{ Gender } \\
\hline Male & 3 & 6 & 5 & 14 \\
\hline Female & 2 & 0 & 2 & 4 \\
\hline TOTAL & 5 & 6 & 7 & 18 \\
\hline \multicolumn{5}{|l|}{ Education } \\
\hline College & & 1 & & 1 \\
\hline $\begin{array}{l}\text { Some } \\
\text { Univer- } \\
\text { sity }\end{array}$ & 2 & & & 2 \\
\hline Bachelor & 1 & 3 & 2 & 6 \\
\hline Masters & 2 & 1 & 5 & 8 \\
\hline Ph. D. & & 1 & & 1 \\
\hline TOTAL & 5 & 6 & 7 & 18 \\
\hline \multicolumn{5}{|l|}{ Pre-CIO Role } \\
\hline Technical & 2 & 5 & 6 & 13 \\
\hline Business & 3 & 1 & 1 & 5 \\
\hline TOTAL & 5 & 6 & 7 & 18 \\
\hline
\end{tabular}

There were eighteen participants involved in the interviews, which represent a convenience sample. It is very difficult to obtain permission to conduct in depth interviews with senior executives such as CIOs. It is interesting to note the gender differences across the countries of those who volunteered to participate in the project. There were no females who participated from Taiwan. Of the seven participants from the United States two are female; and two of the five CIOs from New Zealand are female. It is also interesting to note that the majority of CIOs from both the United States and Taiwan had technical experience before they became CIO. However, in New Zealand the majority came from a business background. Because of the very small sample size relative to the overall population of CIOs in each country it is not possible to make a generalized statement about gender differences or pre-CIO role experience. However, the following comments related to chronological issues in the performance of the CIO role based upon those individuals who were interviewed represents a contribution to further understanding this evolving role.

Table 3 shows the raw count of issues. The data in this table are organized by country and then whether the issue was oriented towards either a technical of management consideration (with an indication of relative size). Further, the data are presented based upon the chronological sequence of Initial, Current, and Future Issues. 
Table 3. Count of Issues

\begin{tabular}{|l|c|c|c|}
\hline & New Zealand & Taiwan & United States \\
\hline & Technical : Management & Technical : Management & Technical : Management \\
\hline Initial & $9<14$ & $5<8$ & $11<14$ \\
\hline Current & $6<13$ & $10>9$ & $7<12$ \\
\hline Future & $5<9$ & $13>3$ & $6<15$ \\
\hline
\end{tabular}

This overall presentation in Table 3 facilitates the identification of a trend in emphasis of issues. Note that the trend for New Zealand and United States is the same chronologically with a consistent emphasis on management. The Taiwan data show a change in emphasis from initially a management orientation to a technical emphasis for current and future issues.

As presented later in this manuscript, culturally New Zealand and United States are more similar to each other, and Taiwan is less similar to either. In relation to Hofstede's $(1980,1983,1993$, 2001) five dimensions of cultural variability, two may be employed to attempt to explain the differences in the trends identified in Table 3. The two dimensions are Individualism/Collectivism and Uncertainty Avoidance. Together these two dimensions suggest that the culture in Taiwan will tend to form tightly knit groups with mutual dependencies and obligations that will develop strict rules and codes of behaviour. Thus, CIOs in Taiwan may more easily address management issues allowing for a focus on technical considerations.

The more detailed discussion of the findings is organized from two perspectives. To begin, issues are identified based upon those that the CIO initially responded to, then issues that are currently being addressed, and finally those that are anticipated in the future. This chronological presentation relates to how the discussion was conducted during the interview and is a standard approach within Narrative Inquiry. Further, within each Issues sub-section the discussion is presented in relation to management, both within the functional unit and the overall company, and technical aspects. This presentation relates to the major contextual aspects within which the $\mathrm{CIO}$ role is performed. Table 4 presents an overview of the issues that are discussed below.

Table 4. Issues

\begin{tabular}{|c|c|c|c|}
\hline $\begin{array}{l}\text { Context of the } \\
\text { CIO Role }\end{array}$ & Initial & Current & Future \\
\hline $\begin{array}{l}\text { Management of the } \\
\text { Function }\end{array}$ & $\begin{array}{ll}\text { - } & \text { Workforce } \\
\text { - } & \text { Re-organization } \\
\text { - } & \text { Legacy systems } \\
\text { - } & \text { Project Man- } \\
& \text { agement Office } \\
\end{array}$ & $\begin{array}{ll}\text { - } & \text { Soft skills } \\
\text { - } & \text { Technical skills }\end{array}$ & $\begin{array}{ll}\text { - } & \text { Performance } \\
\text { standards } \\
\text { - } & \text { Staffing }\end{array}$ \\
\hline $\begin{array}{l}\text { Management of the } \\
\text { Company }\end{array}$ & $\begin{array}{ll}\text { - } & \text { Business proc- } \\
\text { esses } \\
\text { - } \\
\text { - } \text { Usmmunication } \\
\text { - Regulators }\end{array}$ & $\begin{array}{ll}\text { - } & \text { Governance } \\
\text { - } & \text { Business and } \\
\text { information } \\
\text { systems profes- } \\
\text { sionals } \\
\text { - } \\
\text { Business intel- } \\
\text { ligence }\end{array}$ & $\begin{array}{ll}\text { - } & \text { External relations } \\
\text { - } & \text { Governance } \\
\text { - } & \text { Outsourcing } \\
\text { - } & \text { Cost reduction } \\
& \end{array}$ \\
\hline Technical & $\begin{array}{ll}\text { - } & \text { Standards } \\
\text { - } & \text { vendors }\end{array}$ & $\begin{array}{ll}\bullet & \text { VOIP } \\
\bullet & \text { RFID }\end{array}$ & $\begin{array}{ll}\text { - } & \text { RFID } \\
\text { - } & \text { Data warehouse } \\
\text { - } & \text { Internet security }\end{array}$ \\
\hline
\end{tabular}




\section{Initial Issues}

This section includes a discussion of issues that the participant had to deal with upon assuming the role of CIO. The issues are organized by aspects related to management of the function, management of the company, and technical.

\section{Management of the function}

Initially the CIO may have encountered a demoralized workforce within the CIO's functional area. This situation may have resulted from the information systems staff being overworked or because they were under-performing. Further, staff may become demoralized because their contribution has not been recognized throughout the company. A general response to the demoralized staff and to gain more recognition for staff accomplishments included various forms of public celebration. Financial rewards must be reserved for performance incentives. However, nonfinancial celebrations may involve plaques or certificates or newsletters to announce initiatives as well as accomplishments.

Functional re-organization was another issue dealt with initially. Some of the CIOs were hired with the express purpose of re-organizing the information systems function and to set a new direction for the provision of information systems services within the company. Other CIOs felt the necessity to re-organize to facilitate the alignment of the information systems unit with the overall company goals. In either case, jobs and skill sets changed resulting in re-assignment or termination of some individuals. These changes were a consequence of the CIOs desire to have the right people in the right places.

The CIO was usually hired because the company was growing and there was senior management recognition that the business processes required revision. Thus, a plan was necessary for revising and updating legacy systems and perhaps integrating new systems and technology. Further, it was important to decide which specific functions would be outsourced.

In many initial situations a project management office was established in response to the increased number of projects. Standard operating procedures were established for carrying out projects. Responsibilities of project managers were documented. Expectations for user participation were developed and agreed upon. The process of setting project priorities was established.

\section{Management of the company}

In some cases the CIO role was established to facilitate major revisions to the business processes. It was determined that a senior management position in the form of a $\mathrm{CIO}$ would be required not only to apply new information technology but also to develop a revised corporate culture towards conducting business. It was generally recognized by the participants in this project that the cultural change was more difficult to effect than any technical change.

Communication with all levels of users was initially required to gain an understanding of the general attitude toward information technology. This communication was mainly accomplished through face-to-face meetings.

There may have been dissatisfied users because of a prior lack of performance or simply poor communication. In both cases the establishment of a help desk to respond to the immediate needs of users represented a first step towards resolving dissatisfaction.

Depending upon the industry, it may be necessary for the company to work with government regulatory bodies. It may also be necessary for the CIO to become involved to ensure any new or revised application of technology complies with established industry regulations. 
Because the role was relatively new, the CIO would have to initiate a governance program. It is necessary to demonstrate to all senior managers that they are responsible for business decisions involving the use of information technology.

\section{Technical}

Initially from a technical perspective it was important that the CIO adopted standards. A more efficient operation is possible through the standardization of infrastructure. This means common operating systems, computers, and networks. This common approach could result in significant financial savings when establishing contracts with vendors.

\section{Current Issues}

Another set of questions posed during the interviews related to issues currently being addressed by the CIO. The presentation here is organized in the same manner as the previous section.

\section{Management of the function}

The major activity is related to attempting to ensure the availability of appropriate skills. Soft skills such as ability to communicate are considered important. Other soft skills included managing people and working as a team member. The acquisition of technical skills will require a specific training program for each company depending upon the combination of legacy systems, cross-functional systems, and e-commerce applications.

\section{Management of the company}

Issues were also identified that relate to the overall company.

Governance is a current issue that is attracting a lot of attention. All senior managers must realize they retain the responsibility for decisions relating to information systems and the use of information technology.

The CIO must manage the gap between business professionals who know the business and the information systems professionals who know the technology. Each group should be encouraged to attempt to understand the perspective of the other group.

Several companies are in various stages of implementing an ERP system. These systems address many goals. An ERP system will facilitate decision making within the firm. It will support the sharing of information with business partners. An ERP system can facilitate a corporate level cultural transformation towards a more service orientation. Also, many companies are incorporating the concept of business intelligence to support managers dealing with the vast amount of information that is available through the use of information technology. Data warehouses form the base for ERP systems and may be queried in many different ways through the use of data mining techniques.

Related to both ERP system implementations and the business intelligence initiative is the "War Room". This is a meeting room where senior managers, with the assistance of state of the art technology, can make effective corporate level decisions.

\section{Technical}

Various types of technologies are being investigated and applied to improve business processes. These technologies include VOIP, wireless communications, and RFID. A major technology issue is supply chain management including managing inventory and sharing production plans with suppliers. 


\section{Future Issues}

The future is considered both interesting and challenging. This section includes a discussion of those major issues identified by the CIO. Again, the section is organized by aspects related to management of the function, management of the company, and technical.

\section{Management of the function}

The two issues that CIOs anticipate addressing in the future for their own business unit relate to personnel. One issue relates to the establishment of performance standards. CIOs will be looking for an independent assessment model. Another issue will be about staffing. It will be important to ensure the availability of the appropriate skills mix, either through hiring new employees or training current staff.

\section{Management of the company}

The CIOs interviewed anticipate dealing more with external entities such as suppliers, customers, and regulators. For example, e-commerce web sites promote interaction with those entities as well as international expansion.

Governance, as presented earlier, will continue to be an issue to be addressed by the CIO. The senior management team must be cognizant of the ramifications of their decisions regarding the use of information technology.

If outsourcing is going to be employed by the company to provide service and access to necessary skills for information technology deployment, then off-shore outsourcing should be considered. This approach will introduce issues surrounding language and culture and may necessitate an increased level of communication.

Finally, some CIOs anticipate further use of information technology to reduce costs throughout the company. Thus, information technology will be employed in support of the adoption of the concept of the lean enterprise.

\section{Technical}

The future will see the adoption of technologies such as mobile devices and RFID to support or change business processes. Data warehouses will be implemented to support the business intelligence initiative. As more companies adopt Internet-based systems security becomes an issue.

\section{Discussion}

This investigation determined specific aspects related to alignment (Reich \& Benbasat, 2000; Seddon, Graeser, \& Willcocks, 2002) of the interpretation of the individual role and the corporate expectations as expressed by the CEO. This alignment may be expressed as follows. The role of a CIO may include leadership and facilitating change. The role of the Chief Technology Officer (CTO) has more to do with management and ensuring efficient current operations. While leadership involves creating vision and inspiring followers, management involves implementing programs within the established vision and evaluating performance of followers relative to established metrics. Both of these functions, CIO and CTO, are important. What is more important is the alignment or agreement between the $\mathrm{CEO}$ and the $\mathrm{CIO}$ that the role will involve those aspects associated with a CIO role or a CTO role. Interpretations of both the CIO and the CEO must be clear and explicit.

Dearstyne (2006) has suggested that successful CIOs adopt strategies related to the following aspects. They must thoroughly understand the organization through a lengthy involvement both within the industry as well as the specific firm. Further, they must be able to manage expecta- 
tions. This requires successfully establishing relationships with peers as well as those who report directly to the CIO. Both of these strategies will result in roles that are significantly influenced by the organizational environment and will contribute to the necessary alignment of role and expectations.

The CIO roles differ from the role of other senior managers. Grover, Jeong, Kettinger, and Lee (1993) suggest that the unique aspects of information systems have contributed to the relative uniqueness of the $\mathrm{CIO}$ role. Further, they suggest that the $\mathrm{CIO}$ role is different from that of lower level information systems managers. The CIO must adopt a perspective beyond the business unit through interactions with other parts of the organization as well as external entities, such as suppliers, vendors, or regulators. The role of the CIO is influenced by the information technology maturity environment of the organization (Grover et al., 1993; Pearson \& Chaterjee, 2003).

Another major thrust of this investigation was related to culture. Law and Ngai (2007) investigated the reporting relationships between CEOs and CIOs in multinational and Hong Kong based firms with operations in China. They also assessed senior management support for the CIO. They determined that senior management support and a close reporting relationship between CEOs and CIOs facilitated improved performance regarding business process improvement (BPI) and IT infrastructure capabilities. They conclude that the role of CIO is mainly affected by enterprise objectives.

Lindstrom, Johnson, Johansson, Ekstedt, and Simonsson (2006) conducted a survey of Swedish CIOs regarding issues and constraints of their role within the organization. The results suggest that highest priority concerns are related to the following:

- Decreasing IT costs within the organization

- Improving the relationship between IT and business parts of the organization

- Implement novel computer-aided support for the business part of the organization

They also determined that CIOs of larger companies possessed a more business-oriented focus than CIOs in smaller firms.

While these two investigations were conducted individually and in different cultures, they, in effect, determined similar results. Table 5 presents a comparison of the above two investigations and shows how they are similar.

Table 5. Comparison of Investigations

\begin{tabular}{|c|c|c|}
\hline Concept & Lindstrom et al. (2006) & Law and Ngai (2007) \\
\hline Business Operations & Computer-aided support & BPI \\
\hline Internal IT Operations & IT Costs & ITC \\
\hline Interdepartmental Relations & Improving & Mediating between divisions \\
\hline
\end{tabular}

This similarity of results between investigations in Sweden and Hong Kong responds to the question about cultural differences. In general, there exist two hypotheses regarding cross-cultural research (Ronen, 1986; Webber, 1969; Yang, 1986). One hypothesis, "convergence", suggests that cultures are becoming more similar through globalization and the pervasive use of common technologies. The other hypothesis, "divergence", suggests that cultures strive to retain their distinctiveness. 
Hofstede $(1980,1983,1993,2001)$ proposed that it is possible to distinguish cultures based upon five dimensions. Table 6 presents Hofstede's cultural dimensions for the countries involved in this investigation.

Table 6. Hofstede's Cultural Dimensions Indexes

\begin{tabular}{|l|c|c|c|c|c|}
\hline \multirow{2}{*}{ Country } & \multicolumn{5}{|c|}{ Cultural Dimensions } \\
\cline { 2 - 6 } & $\begin{array}{c}\text { Individualism/ } \\
\text { Collectivism }\end{array}$ & $\begin{array}{c}\text { Power } \\
\text { Distance }\end{array}$ & $\begin{array}{c}\text { Uncertainty } \\
\text { Avoidance }\end{array}$ & $\begin{array}{c}\text { Masculinity/ } \\
\text { Femininity }\end{array}$ & $\begin{array}{c}\text { Long/Short Term } \\
\text { Orientation }\end{array}$ \\
\hline New Zealand & 79 & 22 & 49 & 58 & 30 \\
\hline Taiwan & 17 & 58 & 69 & 45 & 87 \\
\hline United States & 91 & 40 & 46 & 62 & 29 \\
\hline
\end{tabular}

Source: Hofstede (1980)

For the most part New Zealand and the United States are similar across the cultural dimensions. The Taiwan culture tends to be either higher or lower on all dimensions. So, it would be expected that New Zealand and the United States would have similar cultures, while that of Taiwan would be different.

Individualism/Collectivism. New Zealand and the United States are placed more toward the Individualism end of the dimension while Taiwan is placed more toward the Collectivism end. Thus, individuals in Taiwan will tend to form tightly knit groups with mutual dependencies and obligations.

Power Distance. There is variability across all three countries with regards to Power Distance. High Power Distance cultures (Taiwan) tend to accept an unequal distribution of power within society. Low Power Distance cultures (New Zealand) tend to strive for equal power and participation. In this investigation the United States falls between the other two countries.

Uncertainty Avoidance. Taiwan scores higher on Uncertainty Avoidance which suggests that cultures attempt to control uncertainty through strict rules and codes of behaviour. New Zealand and the United States score closely together suggesting these cultures avoid controls and deviation is more accepted.

Masculinity/Femininity. These scores for the three countries are relatively similar. New Zealand and the United states score more towards the masculine dimension which suggests a culture which emphasizes achievement, success, and assertiveness. Taiwan scores more toward the feminine dimension suggesting an emphasis on caring, close relationships, and harmony.

Long/Short Term Orientation. Taiwan scores relatively very high with regards to a long term orientation suggesting a focus on building relationships. New Zealand and the United States score virtually the same more towards the short term dimension suggesting a focus on immediate results.

Thus, based upon Hofstede's cultural dimensions, it would be expected that individuals in the Taiwan culture, relative to the culture of New Zealand and the United States, would be more collective, accept unequal power distribution, establish codes of behaviour to avoid uncertainty, and take a long term perspective to relationships.

However, the contention here is that organizational culture has a greater effect than societal culture. Thus, the roles played by the CIOs are dependent upon the specific organization and its environment. Pearson and Chatterjee (2003) provide support suggesting that the operationalization of these roles is carried out in a manner reflective of the specific corporate culture and contextual 
nuances of specific local practices. However, while the roles may be the same, how they are performed may be influenced by such environmental aspects as societal culture.

Thus, organizational culture, as a reflection of societal culture, will to a large extent influence how a role is played. Further, the CIO role will be influenced by senior management expectations. Thus, it is incumbent upon the CIOs to assess and manage how their peers interpret the deployment of information technology within the organization.

\section{Conclusion}

This investigation determined the importance of alignment between senior management expectations and the role played by the CIO. Indeed, it is incumbent upon both parties to clearly enunciate their expectations.

With regards to culture, while some variability was determined in the overall trend data, none was found at the more detailed level of issues. The overall trend data shows that the Taiwan CIOs, because of their cultural emphasis on Hofstede's $(1980,1983,1993,2001)$ dimensions of Individualism/Collectivism and Uncertainty Avoidance, could more easily resolve management issues than could the CIOs involved in this investigation from New Zealand and the United States.

However, at the detailed level of issues there was very little difference among the three groups of research participants. This similarity could be the result of training and experience in technologies and techniques that have originated in the western cultures. Thus, while the culture of Taiwan differs from those of New Zealand and the United States, the roles performed by CIOs are more influenced by the origination in western cultures of the major components of work performed by the CIO. Grover et al. (1993) suggest that the roles played by the CIOs are dependent upon the specific organization and its environment. Pearson and Chatterjee (2003) support this conclusion. It was determined in this investigation that corporate culture takes precedence over societal culture. Thus, organizational culture, rather than societal culture, will to a large extent influence how a role is played. The concept of organizational culture and the relationship with information technology has been proposed by Travica $(2005,2008)$. Employing the term "infoculture" (Travica, 2003) or information culture, it has been suggested that the culture of the organization is impacted by the adoption and use of information technology. Further, the CIO role will be influenced by senior management expectations. Thus, it is incumbent upon the CIOs to assess and manage how their peers interpret the deployment of information technology within the organization and to attempt to understand the specific organization's infoculture.

Thus, CIOs to be successful must focus upon an industry. The experience of the CIOs involved in this investigation suggested that they either worked or consulted in one specific industry. It becomes a very high risk approach for a $\mathrm{CIO}$ to change industries. As the $\mathrm{CIO}$ role takes on more of a business emphasis it becomes more important that the specific individual brings the necessary industry experience.

Finally, this research project represents an in-depth investigation of the role of the CIO. The results of this project contribute to a more thorough understanding of the role of the $\mathrm{CIO}$ and how the role is evolving in various corporate and national contexts.

\section{References}

Andrews, P., \& Carlson, T. (1997). The CIO is the CEO of the future. Proceedings of the CIO Conference, www.cio.com/conferences/eds/sld018.htm

Andriole, S. J. (2009). Boards of directors and technology governance: The surprising state of the practice. Communications of the Association for Information Systems, 24(1), 373-394.

Arnold, M. A. (2001). Secrets to CIO success. Credit Union Management, 24(6), 26. 
Bassellier, G., Gagnon, E. \& Pinsonneault, A. (2008). CIO and CEO heterogeneity, IT support, and IT competitiveness in stable and unstable environments: An empirical study. AMCIS 2008 Proceedings, Toronto, Canada, August 14-17.

Bharadwaj, A. S. (2000). A resource-based perspective on information technology capability and firm performance: An empirical investigation. MIS Quarterly, 24(1), 169-196.

Bharadwaj, A. S., Sambamurthy, V., \& Zmud, R. W. (1999). IT capabilities: Theoretical perspectives and empirical operationalization. International Conference on Information Systems, Charlotte, NC.

Blair, R. (2005). The future of CIOs. Health Management Technology, 26(2), 58-59.

Bock, G., Carpenter, K., \& Davis, J. E. (1986, October 13). Management's newest star - Meet the Chief Information Officer. Business Week, No. 2968, 160-166.

Capella, J. (2006). The CIOs first 100 days. Optimize, 5(3), 46-51.

Cash, J. (2005). Your new market mandate: Meet the customer. CIO, 18(22), 1-3.

Dickerson, C. (2004). Get technology right. InfoWorld, 26(7), 26.

Dittmar, L., \& Kobel, B. (2008). The risk intelligent CIO. Risk Management, 55(3), 42.

Dearstyne, B. W. (2006). CIOs: Information program leaders in transition, The Information Management Journal, 40(1), 44-50.

Earl M. J., \& Feeny, D. F. (1994). Is your CIO adding value? Sloan Management Review, 35(3), 11-20.

Feeny, D. F., \& Willcocks, L. P. (1998a). Core IS capabilities for exploiting information technology. Sloan Management Review, 39(3), 9-21.

Feeny, D. F., \& Willcocks, L. P. (1998b). Redesigning the IS function around core capabilities. Long Range Planning, 31(3), 354-367.

Feld, C. S., \& Stoddard, D. B. (2004). Getting IT right. Harvard Business Review, February, 72-79.

Glaser, B. G., \& Strauss, A. L. (1976). The discovery of grounded theory: Strategies for qualitative research. New York, Aldine DeGruyter.

Grover, V., Jeong, S., Kettinger, W., \& Lee, C. C. (1993). The Chief Information Officer: A study of managerial roles. Journal of Management Information Systems, 10(2), 107-131.

Hartung, S., Reich, B. H., \& Benbasat, I. (2000). Information technology alignment in the Canadian Forces. Canadian Journal of Administrative Sciences, 17(4), 285-302.

Hofstede, G. (1980). Culture's consequences: International differences in work-related values. Beverley Hills, CA: Sage Publications.

Hofstede, G. (1983). The cultural relativity of organizational practices and theories. Journal of International Business Studies, Fall, 75-89.

Hofstede, G. (1993). Cultural constraints in management theories. Academy of Management Executive, 7, 81-94.

Hofstede, G. (2001). Culture's consequences: Comparing values, behaviors, institutions, and organizations across nations. Thousand Oaks, CA: Sage Publications.

Johnson, A. M., \& Lederer, A. L. (2007). The impact of communication between CEOs and CIOs on their shared views of the current and future role of IT. Information Systems Management, 24(1), 85-90.

Jones, M. C., \& Arnett, K. P. (1994). Linkages between the CEO and the IS environment. Information Resources Management Journal, 7(1), 20-33.

Kaarst-Brown, M. (2005). Understanding an organization's view of the CIO: The role of assumptions about IT. MIS Quarterly Executive, 4(2), 287-301. 
Karimi, J., Bhattacherjee, A., Gupta, Y. P., \& Somers, T. M. (2000). The effects of MIS steering committees on information technology management sophistication. Journal of Management Information Systems, 17(2), 207-230.

Kolbasuk, M. (2005). CIOs get respect. Insurance and Technology, 30(9), September, 18.

Korn/Ferry International. (1998). The changing role of the Chief Information Officer. London.

Law, C. C. H. \& Ngai, E. W. T. (2007). IT infrastructure capabilities and business process improvements: Association with IT governance characteristics. Information Resources Management Journal, 20(4), $25-47$.

Lindstrom, A., Johnson, P., Johansson, E., Ekstedt, M., \& Simonsson, M. (2006). A survey on CIO concerns - Do enterprise architecture frameworks support them? Information Systems Frontiers, 8, 81-90.

Maciag, G. A. (2002, August 19). The CIO challenge: Bridging the gap between IT and CEO. National Underwriter, 106(33), 33-34.

Marchand, D. A. (2008). The Chief Information Officer - Achieving credibility, relevance and business impact. Perspectives for Managers, IMD, No. 164.

McCracken, G. (1988). The long interview. New York: Sage Publications.

McKeen, J. D., Smith, H., \& Jin, J. (2009). Developments in practice XXXII: Successful strategies for IT staffing. Communications of the Association for Information Systems, 24(1), 805-820.

Meagher, R. (2003). Putting 'strategic' into information management. The Information Management Journal, January/February, 51-57.

Miles, M. B., \& Huberman, A. M. (1994). Qualitative data analysis: A new sourcebook of methods (2nd ed.). Newbury Park, CA: Sage Publications.

Newbold, D. L., \& Azua, M. C. (2007). A model for CIO-led innovation. IBM Systems Journal, 46(4), 629637.

Nolan Norton Institute. (2001). Say goodbye to the CIO, Welcome to the business prophet. Information Management and Computer Security, 9(2/3), 123-125.

Olson, L. A. (2000, May 8). The strategic CIO - Lessons learned, insights gained. Information Week, 785, 264.

Patten, K. P., Fjermestad, J., \& Whitworth, B. (2009). How CIOs use flexibility to manage uncertainty in dynamic business environments. AMCIS 2009 Proceedings, San Francisco, California, August 6 - 9.

Pearson, C. A. L., \& Chatterjee, S. R. (2003). Managerial work roles in Asia: An empirical study on Mintzberg's role formulation in four Asian countries. Journal of Management Development, 22(7/8), 694707.

Peppard, J. (2007). The conundrum of IT management. European Journal of Information Systems, 16, 336345.

Ranganathan, C., \& Jha, S. (2008). Do CIOs matter? Assessing the value of CIO presence in top management teams. ICIS 2008 Proceedings, Paris.

Reich, B. H., \& Benbasat, I. (2000). Factors that influence the social dimension of alignment between business and information technology objectives. MIS Quarterly, 24(1), March, 81-113.

Reich, B. H., \& Nelson, K. M. (2003). In their own words: CIO visions about the future of in-house IT organizations. ACM SIGMIS Database, 34(4), 28-44.

Ronen, S. (1986). Comparative and multinational management. New York: John Wiley.

Scholes, R. (1981). Language, narrative, and anti-narrative. In W. Mitchell (Ed.), On narrativity (pp. 200208). Chicago: University of Chicago Press. 
Scott, J. E. (2007). Mobility, business process management, software sourcing, and maturity model trends: Propositions for the IS organization of the future. Information Systems Management, 24(2), 139-145.

Seddon, P. B., Graeser, V., \& Willcocks, L. P. (2002). Measuring organizational IS effectiveness: An overview and update of senior management perspectives. The Database for Advances in Information Systems, 33(2), 11-28.

Stephens, C. S., Ledbetter, W. N., Mitra, A., \& Foord, F. N. (1992). Executive or functional manager? The nature of the CIO's job. MIS Quarterly, 16(4), 440-467.

Stephens, C. S., \& Loughman, T. (1994). The CIO's chief concern: communication. Information and Management, 27(2), 129-137.

Stewart, V., \& Stewart, A. (1981). Business applications of repertory grid, London: McGraw-Hill.

Swap, W., Schields, M., \& Abrams, L. (2001). Using mentoring and storytelling to transfer knowledge in the workplace. Journal of Management Information Systems, 18(1), 95-114.

Thompson, C. J. (1997). Interpreting consumers: A hermeneutical framework for deriving marketing insights from the texts of consumers' consumption stories. Journal of Marketing Research, 34(November), 438-455.

Todd, P. A., Mckeen, J. D., \& Gallupe, R. B. (1995). The evolution of IS job skills: A content analysis of IS job advertisements from 1970 to 1990. MIS Quarterly, 19(1), 1-27.

Travica, B. (2003). Information view of organization: Contextualizing technology - technologizing context, American Conference on Information Systems, Tampa, FL.

Travica, B. (2005). Information politics and information culture: A case study. Informing Science Journal the International Journal of an Emerging Transdiscipline, 8, 211-244. Retrieved from http:/www.inform.nu/Articles/Vol8/v8p211-244Travica.pdf

Travica, B. (2008). Influence of information culture on adoption of self-service system. Journal of Information, Information Technology, and Organization, 3, 1-15. Retrieved from http://jiito.org/articles/JIITOv3p001-015Travica470.pdf

Tulving, E. (1972). Episodic and semantic memory. In E. Tulving \& W. Donaldson (Eds.), Organization of memory (pp. 381-404). New York: Academic Press.

Van der Heijden, H. (2001). Measuring IT core capabilities for electronic commerce. Journal of Information Technology, 16, 13-22.

Webber, R. H. (1969). Convergence and divergence. Columbia Journal of World Business, 4(3), 75-83.

Weiss, J. W., \& Anderson, D. (2004). CIOs and IT professionals as change agents, risk and stakeholder managers: A field study. Engineering and Management Journal, 16(2), 13-18.

Weiss, J. W., Thorogood, A., \& Clark, K. D. (2006). Three IT-business alignment profiles: Technical resource, business enabler, and strategic weapon. Communications of the Association for Information Systems, 18(1), 676-691.

Yang, K. S. (1986). Will societal modernization eventually eliminate cross-cultural psychological differences? In M. H. Bond (Ed.), The cross-cultural challenge to social psychology. Newbury Park, CA: Sage.

Yayla, A. A., \& Hu, Q. (2009). The impact of IT-business strategic alignment on firm performance: The role of environmental uncertainty and business strategy. AMCIS 2009 Proceedings, San Francisco, California, August 6-9. 


\section{APPENDIX}

\section{INTERVIEW PROTOCOL}

\section{PART A}

1. Personal History
a. Where were you born?
b. Where did you grow up?
c. Are you married?
d. Any children?
e. Please relate a personal interest story.

2. Family History
a. Parents
b. Siblings
c. Where you lived

3. Education

a. Where and when did you go to elementary school, high school and university?

4. Previous Work Experience
a. What companies have you worked for?
b. What positions have you held at these companies?
c. What were the highlights as far as tasks performed and major accomplishments?

\section{PART B}

5. Current Position

a. Company background

i. What is the industry?

ii. When was the company formed?

iii. What is the company's industry relationship (market share)?

iv. What is the company Mission?

v. Are there any unique aspects to the company that you find interesting?

vi. What is the URL for your website?

b. Why did you accept your current position?

c. What issues initially required your attention?

i. Describe the issue.

ii. Discuss what you did.

iii. Discuss the final result.

iv. Repeat the above for another issue.

d. What issues are you currently addressing?

i. Describe the issue

ii. Discuss the status and anticipated outcome.

iii. Repeat the above for another issue.

e. What issues do you foresee addressing or requiring your attention in the future?

i. Describe.

ii. How do you plan to address the issue?

iii. What is the anticipated outcome?

iv. Repeat the above for another issue. 


\section{PART C}

6. Pick a week and tell me what you did

a. Describe the task

b. Indicate the number of hours you spend doing the task

c. Was there something that you did not do that week that you normally would?

7. Dealing with Users.

a. How do you determine what your users want/require?

b. How do you know that you have responded to what your users want/require?

c. How do you know that you have delivered what your users want/require?

8. How do you decide on investments in:
a. Hardware?
b. Software?
c. People?
d. Tools?
e. Techniques and methods?

9. General comments about CIOs and their management experiences.

\section{Biography}

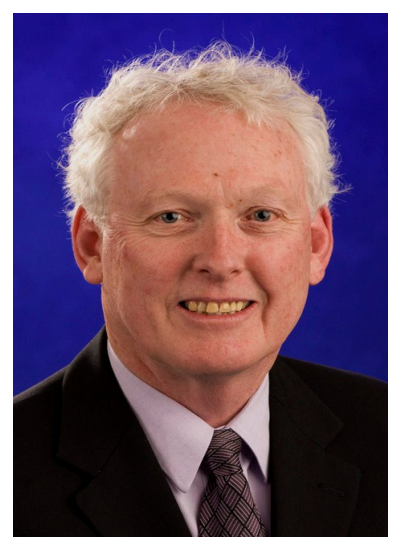

Dr. M. Gordon Hunter is a Professor Information Systems in the Faculty of Management, University of Lethbridge, Alberta, Canada. He has also been appointed Visiting Professor, London South Bank University. He has held visiting positions at universities in Australia, England, Germany, Monaco, New Zealand, Poland, Turkey, and USA. In 2009 Gordon was a Fellow at the University of Applied Sciences, Munich, Germany. During 2005 Gordon was an Erskine Fellow at the University of Canterbury, Christchurch, New Zealand. Gordon's research approach takes a qualitative perspective employing Personal Construct Theory and Narrative Inquiry to conduct in depth interviews. He applies qualitative techniques in interdisciplinary research such as Multi-Generation Small Business, Community-Based Organizations, and cross-cultural investigations. His current research interests in the information systems (IS) area include the effective management of IS with emphasis on the personnel component; the role of Chief Information Officers; and the use of IS by small business. 